\title{
Pondering over a brand-new development pattern of campus P. E. culture construction
}

\author{
Li Yuming \\ P. E. College, Baicheng Normal University, Baicheng 137000, China
}

\section{Email address:}

Liyuming2000@163.com

\section{To cite this article:}

Li Yuming. Pondering over a Brand-New Development Pattern of Campus P. E. Culture Construction. Education Journal. Vol. 3, No. 6, 2014, pp. 319-322. doi: 10.11648/j.edu.20140306.11

\begin{abstract}
Sports culture of university campus is an important component in campus culture which virtually influences both teachers and students with its unique cultural atmosphere. A good campus P. E. cultural atmosphere is the foundation to realize China Dream. However, with the development of society and the progress of education, some problems appeared in current construction of campus P. E. culture. This paper analyzed the existing problems based on the features and functions of university campus sports culture, proposed the approaches of constructing a brand-new development pattern so as to drive university campus cultural construction into a brand-new developmental period.
\end{abstract}

Keywords: University, Campus Sports Culture, Development, Pondering Over

China Dream has become everyone's pursuit in China since General Secretary Xi Jin ping advocated in his important speech on March 17th, 2013. Universities are the main social carrier in cultural accumulation, development and inherit. They are supposed to put moral composition into practice, cultivate students' social responsibility, innovate spirits and practical ability and constantly improve talents training quality. This is because university students are not only the dreamy group, but also the subject of campus culture, while sports culture is the key part of campus culture which influences both teachers and students tangibly and intangibly. However, with the development of society and the progress of education, some problems gradually appeared in the construction of current campus sports culture, and how to take the advantage of campus cultural construction to promote China Dream is a whole new research topic. This paper put forward some approaches to enhance university campus sports culture in order to push the construction of campus culture and build a good campus sports culture atmosphere and serve talents training.

\section{Conception and Constitution of Campus Sports Culture}

\subsection{Conception}

Campus sports culture is the subculture under the circumstance of specific campus culture, it is both a branch of social culture and the main component of campus culture. It takes campus as space, takes students and teachers' participation as subject, and is characterized by campus spirit, focuses on talents training, uses physical exercises as methods, regarding various sports exercise events as the main content, and it is a community culture with unique pattern of manifestation. [1]

Campus sports culture is a cultural phenomenon which owns profound connotation and abundant extension which constitutes campus cultural group with moral education, intellectual education and aesthetic education cultures. It forms sports education group with competitive sports culture and mass sports culture.

\subsection{Constitution}

The construction of campus sports culture is one of the important contents to realize the campus' harmonious development, in order to achieve this goal, sports cultural construction should be enhanced. University campus P. E. culture includes material culture, behavioral culture, institutional culture, and spiritual culture. Firstly, material culture is the foundation and extrinsic symbol, it is made up of athletic facility, sports building, site equipment and sportswear. Secondly, behavioral culture is the power of university campus P. E. culture, which includes physical education teaching, training, competition, extracurricular 
athletics, and sports performance. To some extent, it has mandatory role to the sports behavior of the participants, it is the reflection of form and content of university campus sports culture. Thirdly, institutional culture consists of sports regulations, rules, and judicial rules. It is the guarantee for universities to carry out sports cultural activities. Fourthly, spiritual culture is referred as sports way of thinking, aesthetic taste and views of sports, sports spirit and morality in people's mind. It is implicit and intangible, and is reflected in the form of human's consciousness, it is actually the soul of university campus sports culture. ${ }^{[2]}$

\section{Features of University Campus P. E. Culture}

University campus sports culture is based on social politics, economy, culture and P. E., in which staff and students are the principal part, sports environment and students' demands play the role of formation. It is a synthesis of fitness, pastime, entertainment and culture transmission. It is the important content of university students' cultural activities.

\subsection{Directionality}

The target of university education is to cultivate the new-typed people who develop very well in moral, intellectual, physical, and aesthetic aspects. And this determined that campus sport culture has to comply with this aim. Therefore, universities have the responsibility to regard P. E. culture as a way of thinking, behavior and lifestyle to teach students, making it possible for them to present themselves, self-educating, self-enhancing; motivating them to do sports scientifically, set up correct world view, life view, values in order to lead P. E. culture develop healthily and correctly.

\subsection{Epochal Character}

Each culture is the product of era, it has certain era characteristics, and varies constantly with era development. In the process of campus culture, its content and form are restricted by political system, economic system, education system and the development social structure at that time, in return, it serves politics and economy. Campus sports culture in different times owns different hotspots and reflects the theme of campus culture at a certain time. Sports spirit could affect campus sports culture, while campus sports culture is the reflection of sports styles in its time. ${ }^{[3]}$

\subsection{High Leveled Feature}

University teachers and students are the main body of campus P. E. culture, and this makes campus culture own high leveled qualities which are demonstrated in culture level, appreciation level, goal pursuit, consumption consciousness and activity design standard. As a high leveled group, they are not simply satisfied with the traditional sports events such as unitary running, play ball games, they long for high leveled campus P. E. culture with the features of current times, ie., the sports product with spirit, culture and sports exercise so as to meet the increasing requirements to P. E. culture. [4]

\subsection{Fairness}

The rules of "Fairness, Justice, and Accuracy" are the most distinguishing features of campus P. E. culture. The corruption phenomena and some unfair things in the society intangibly affect college students. For example, some students don't study hard but hope to cheat in exams. However, in a righteous competition, cheating is impossible. Students would respect objective facts and give themselves objective judgment. Consequently, campus sports culture is significant for students to possess good qualities and comprehensive qualities.

\subsection{Entertainment Feature}

University students are hungry for entertainment activities after they finish their hard studies to adjust their emotion. Campus sports culture exactly satisfies the participants with its universal, self-amusing, and game-play modes. By carrying out pleasing sports activities, participants can obtain happy emotional experience, and the teaching aim of edutainment can be realized. [5] Campus sports culture strongly attracts a large number of teachers and students, the value of which is incomparable compared with other campus cultures.

\section{Functions of University Sports Culture}

\subsection{Educational Function}

University campus P. E. culture educates and cultivates students in the process of training by instructing them with knowledge and skills. P. E. is not only the competition on the playground, but also a multi-subject system. In today's society, students are under a lot of pressures owing to studies and employment. For this reason, P. E. teaching in universities must pay attention to students' mental health and faith education in the course of teaching them specialty knowledge. It should focus on improving their sports knowledge, concept and health levels by arranging teaching, training, taking part in competition and other various sports cultural activities. What's more, they should be shaped the type of people with strong volitional quality and lofty sports morality, and should be optimized and perfected in their personality spirits.

\subsection{Cohesion Function}

Campus sportsmanship and its value system embody the university's cohesive force and centripetal force. A university can be famous not only relies on its theory on school management, formulation of the school's mission, its high teaching quality or high-level sports team, but also the collective force, positive group consciousness and the subjective initiative of the staff agglomerated by campus sports spirit. The fantastic cohesive force and centripetal force produced by campus $\mathrm{P}$. E, culture provides teachers and students a sense of belonging, and enhances their sense of honor and mission. 


\subsection{Fitness Function}

"Fitness ought to be keeping a healthy state in mind, body and society". W.H.O defined the new concept of modern health, illustrating that human health ought to be consisted of body and mind. Colorful campus P. E. culture can precisely meet the health need of teachers and students. By taking part in all kinds of physical trainings, they can strengthen health effectively and develop favorable sports habit, enhance the mind and forge ahead, in the meantime, they can develop collective concept and become the disciplines, and they can also develop the capabilities of coordinating interpersonal relationship, remove mental troubles and improve their emotion, study and work efficiencies.

\subsection{Adjustment Function}

The happy spiritual atmosphere created by campus sports cultural activities asks the teachers and students to participate in colorful sports activities after tense study and work, and attracts them to enjoy all kinds of activities, so that they have more opportunities to contact each other, and remove self-interference and loneliness and the spirit of internal friction. As a result, the relationship between teachers and students will be in harmony, students' intellectual activities can be carried out normally. In one word, a good campus sports culture is beneficial to study, life and work.

\section{Problems Confronted by University Campus P. E. Culture}

Campus sports cultural construction is a systematic engineering, which is not only affected by the ideology of running school, but also affected by P. E. teachers' knowledge, capability, interest, hobby, professional competence, and so forth. In the meantime, the students' perception toward sports culture cannot be ignored. Hence, the problems confronted by universities are as follows:

\subsection{Lack of a Correct P. E. Concept Guidance}

Leaders in most of universities only emphasize school scale, infrastructure construction, teaching management, scientific researches, teaching environment, library construction and so forth. They usually neglect the construction of campus P. E. culture which serves as school image. Although some universities have established sports long-term development plans, set up specialized agencies, and made some control regulations, they never made a refined system to make it normalized, so that it can effectively guarantee sports cultural activities to carry out smoothly. In this sense, the current situation has already hindered campus sports culture's development.

\subsection{Lack of Attaching Importance to P. E. Course}

In recent years, the disproportionality between teachers and students caused by enrollment expansion of universities and colleges formed a situation that the number of teachers is insufficient. More seriously, some universities are short of emphasis on P. E. course, they cut sports course at will in order to improve teaching quality, and even cancelled sports course. While other universities are not willing to offer opportunities to P. E. teachers for further studies, as a result, the intrinsic knowledge fails to be updated and complemented. Besides this, a part of teachers are not aggressive because of being influenced by unhealthy thinking trends, and are not interested in academic researches, and are lack of creative spirit, the sports technique still stays in original level, which prevented campus sports culture from developing well.

\subsection{Weak Consciousness toward Campus Sports Culture}

Most of the teachers thought that campus sports culture was only for building body, and P. E. course was good enough due to the weak consciousness toward campus sports culture. Some teachers even worried about the conflicts among students that sports activities would trigger, so they would ask the organizers to sign Safety Responsibility Statement if the students took part in the sports activities, and this seriously violated the intentions of the most teachers and students, and made them lose interest in sports activities.

\subsection{Lack of Corresponding Sports Facilities}

Students mostly concentrate on their studies in order to be employed well, some old sports facilities are not good enough to attract them, some sports sites are lack of corresponding facilities, therefore, some of them lost their enthusiasm and creative ability in sports exercises, and sports associations are all managed by students themselves, and they always run into some problems. All this was unfavorable to establish a good atmosphere of campus sports culture.

\section{Approaches to Enhance University Campus P. E. Culture}

University campus P. E. culture is the spiritual strength to maintain campus characteristics. Constructing high quality campus P. E. culture is of great significance for universities to absorb achievements of world civilization, to train high quality talents and construct campus spiritual civilization. As far as the author of this paper is concerned, measures should be taken from the following steps in order to enhance university campus sports culture construction.

\subsection{Improve Physical Environment of Campus Sports and Reinforce the Construction of Campus P. E. Cultural Facilities}

Hardware construction in universities like sports facilities appears to be particularly important with the promotion of running school scale and strength. Sports are peculiar for its partialness, the transmission and inheritance of sports culture and mastery of overall knowledge are closely linked with activities and exercises. The space equipment and facilities should be not only valuable in use, but also have cultural 
deposits. Colleges and universities should reinforce the management, development and utilization of sports facilities, and maximize their potential and create more economic and social benefits, so as to accelerate the whole development of sports work and enrich the connotation and denotation of university campus P. E. culture.

\subsection{Have a Clear Guiding Ideology and Advance the Construction of Campus P. E. Culture}

The Central Committee of the Communist Party of China pointed out in the document On Further Enhancing and Improving School's Moral Education Work that construction of campus culture should be emphasized, colorful and positive academic, technological, sports, artistic and entertainment activities should be carried out in order to build healthy and lively campus culture based on socialist culture and national culture. It also put forward that campus environment should be purified hard, the penetration and affection of passive and decadent ideas should be resisted, vulgar culture and irrational culture should be controlled, campus culture needs to be led to an elegant and a healthy development direction. ${ }^{[4]}$ As a part of campus culture, campus P. E. culture ought to serve this guiding ideology.

In the progress of campus P. E. culture, qualities and interest of the teaching staff members and students and competitive sports situations are supposed to be taken into consideration. The teaching ideology of people-oriented should be built, and the fondness of the students needs to be regarded as a turning point, high grade sports activities should be developed on campus, making everyone participate in sports activities, forming characteristics, and making teachers and students have fitness consciousness, team spirit and strong willpower.

\subsection{Open Up Publicity Fronts and Strengthen the Construction of Campus P. E. Culture Consciousness}

Modern information networks has a unique advantage in transmitting speed and capacity, it can transmit the connotation of campus P. E. culture rapidly and ask the students to have a good knowledge of campus sports culture, and can use campus network to set up individualized and multi-functional campus sports culture network, broadcasting station, publicity column and poster, and can fully make the best of P. E. social forum or QQ group, and drive teachers and students' enthusiasm and passion into the activities and thus promote the construction of campus P. E. culture.

\subsection{Deepen P. E. Teaching Reform and Establish a New Pattern of Multiple Concurrent Exercise Forms}

P. E. teaching should start from the features of university P.
E, and choose the appropriate sports events and teaching content for students to attract more students to take an active part, and combine P. E. and health education into one unit. Meanwhile, it should build campus sports cultural atmosphere and by practicing more to train students' willpower, team spirit and consciousness of fair competition. It should realize teachers and students' self-government and self-improvement by introducing P. E. course, P. E. club, individual sports association and sports races and a new pattern of multiple concurrent exercise forms. School P. E. department is responsible for macro-control which is not only beneficial to the mobilization of teachers and students' enthusiasm and their sport techniques and management capability but also to the democratization, legislation and normalization of school's sports work.

\section{Conclusion}

University students are active in thinking, whose mental attitude, educational level, and physical health rely on sports culture to a certain degree. Physical training can help students set up correct world outlook and values. As long as universities stick to the construction of sports culture, students' volitional quality and self-control ability can be fostered. And in the future, they can become highly competent people with confidence, self-improvement and competitive ability to adapt to the society.

\section{References}

[1] Qu Zong-hu, Yang Wenxuan. New field of Vision of After-school Sports[M ] People's Sports Press, 1999,11

[2] CHEN Can-hui. Discussion on the Characteristics of Campus Sports Culture in Colleges and Universities[J]. Journal of Huai hai Institute of Technology (Education Forum. Social Science Edition) ,2010, 5:90-92

[3] MA Wan-feng, XU Jin-hua, XIA Xiao-ping, PING Peng-gang. Discussion of Characteristics and Functions of Campus P. E, Culture in Colleges and Universities[J]. Journal 0f Beijing Univevsity of Physical ducation2003,4:508-510

[4] Shi Xian bin, Chen Fang fang. On the Value of Sports Culture of University Campus under the Background of Cultural Development and Prosperity[J].Journals of Chifeng College (Natural Science Edition), 2013,5:271-272

[5] Wang Genfa. The Construction of University Campus P. E. Culture[J].Journal of Sports Adult Education, 2006,4:28-29

[6] On Further Enhancing and Improving School's Moral Education Work $[\mathrm{N}]$ website of Ministry of Education, 1994.8.31 